\begin{tabular}{|c|c|}
\hline Title & The Effects of the 1.03 million yen Ceiling in a Dynamic Labor Supply Model \\
\hline Author(s) & A be, Y ukiko \\
\hline Citation & $\begin{array}{l}\text { Contemporary Economic Policy, 27(2), 147-163 } \\
\text { https://doi.org/10.1111/ .1465-7287.2008.00115.x }\end{array}$ \\
\hline Issue Date & $2009-04$ \\
\hline Doc URL & http:/hdl .handle.net $/ 2115 / 58492$ \\
\hline Rights & $\begin{array}{l}\text { This is the accepted version of the following article: THE EFFECTS OF THE 1.03 MILLION YEN CEILING IN A } \\
\text { DYNAMIC LABOR SUPPLY MODEL, which has been published in final form at } \\
\text { http://onlinelibrary.wiley.com/doi } / 10.1111 \text {. } 14665-7287.2008 .00115 . x / \text { citedby . }\end{array}$ \\
\hline Type & article (author version) \\
\hline File Information & yukiko_abe_CEP_huscap.pdf \\
\hline
\end{tabular}

Instructions for use 


\title{
The Effects of the 1.03 million yen Ceiling in a Dynamic Labor Supply Model*
}

\author{
Yukiko Abe ${ }^{\dagger}$ \\ April 17, 2008
}

\begin{abstract}
In this paper I examine the effects of a means-tested transfer system in Japan ("1.03 million yen ceiling") in a dynamic labor supply model with endogenous retirement. In Japan, married women have reason to limit their annual earnings to no more than 1.03 million yen in order to receive a number of benefits available to low-income wives, and in fact often choose to do so. In a dynamic model, the optimal labor supply schedule follows a pattern that is not seen in a static framework, which I call the "spillover effect." The paper also examines the properties of dynamic welfare cost of this ceiling.

JEL classification: J22, H24, H55
\end{abstract}

Key words: 1.03 million yen ceiling, part-time work, dynamic labor supply model

${ }^{*}$ I thank Hideo Akabayashi, Shun-ichiro Bessho, Yoshio Higuchi, Jun-ichi Itaya, Toshikazu Kimura, Kenji Miyazaki, an anonymous referee, and seminar participants at Hokkaido University, Kobe University, ISER of Osaka University, and Waseda University for helpful comments. The analysis in Section 2 uses the resampled micro data of the National Survey of Family Income and Expenditure (NSFIE) and the Employment Status Survey (ESS) made available through the Research Centre for Information and Statistics of Social Science, Institute of Economic Research, Hitotsubashi University. For financial support, I thank the Nikkei Foundation; the Japanese Ministry of Education, Science, Sports and Culture Grant to Hosei University on International Research Project on Aging (Japan, China, Korea) (FY2003-FY2007); and the Japan Society for Promotion of Science Grant-in-Aid for Scientific Research (C-17530188). Remaining errors are my own.

Corresponding Author. Graduate School of Economics and Business Administration, Hokkaido University, Kita 9 Nishi 7, Kita-ku, Sapporo, 060-0809 JAPAN. Phone: +81-11-7063860, Fax: +81-11-706-4947, E-mail: abey@econ.hokudai.ac.jp 


\section{Introduction}

The "1.03 million yen ceiling," which in this paper refers to the tendency of married women in Japan who work part-time to limit their earnings to no more than 1.03 million yen (approximately 10,000 US dollars), has recently attracted much attention in policy debates over Social Security and tax reform in Japan. Wives of salaried husbands whose earnings do not exceed 1.03 million yen are eligible to receive several types of benefits. Their benefits include the following: (1) a married woman with low earnings is eligible for Social Security and healthcare benefits through her husband's coverage, with no additional premium contribution for the wife; (2) the husband can claim the 'Exemption for Spouse' or the 'Special Exemption for Spouse' on his income tax return; and (3) the husband often receives an allowance for his spouse from his employer if the wife's earnings are lower than a specified threshold.

The work disincentive effects of the 1.03 million yen ceiling have been pointed out by Higuchi (1995), Abe and Ohtake (1997), Nagase (2001), Akabayashi (2006), and Nagase and Nawata (2005), among others, in the context of static labor supply. In the previous literature, the 1.03 million yen ceiling has been criticized for two reasons. First, it distorts labor supply of married women and causes a loss in efficiency. Evidence shows that the earnings of married, part-time, female workers are heavily concentrated around the one million yen level (Abe and Ohtake 1997, Abe 2003, Oishi 2003, Nagase and Nawata 2005, Akabayashi 2006). If married women are reducing their working hours even though the marginal product of their labor exceeds their marginal disutility from it, then the ceiling is introducing distortions in labor supply. ${ }^{1}$

\footnotetext{
${ }^{1}$ The value of the threshold was 1 million yen from 1989 to 1994 , so analyses using the data
} 
The second criticism is based on equity considerations. Married women who earn less than or equal to 1.03 million yen annually pay no income tax and no Social Security contributions, even though they are eligible for health and public pension benefits through their husbands' coverage. ${ }^{2}$ The wife's earnings up to 1.03 million yen are almost tax-free, while any other middle-income person earning an additional 1 million yen would be taxed at a marginal rate of at least 19 percent. $^{3}$

Although the 1.03 million yen ceiling has attracted much attention, little is known about the dynamic consequences of the ceiling. Previous studies examining the effect of the ceiling on part-time labor supply have almost always used a static framework. However, part-time workers in Japan have a relatively strong attachment to work (Ohtake 2000, Abe 2005). In this paper, I use a simple dynamic labor supply model to assess the behavioral consequences of the 1.03-million-yen ceiling. ${ }^{4}$ The labor supply schedule in a dynamic model has properties that are not present in a static framework, which I call the "spillover effect." The dynamic welfare cost of the ceiling is also discussed.

The rest of the paper is organized as follows. Section 2 provides a brief summary of the Japanese income and Social Security participation rules, and presents

from this period use the phrase " 1 million yen ceiling" instead.

${ }^{2}$ Public pension and healthcare benefits are provided for wives with annual earnings less than 1.3 million yen, instead of 1.03 million yen. Evidence indicates that the incomes of these women are concentrated mainly around 1.03 million yen, however, rather than the 1.3 million yen.

${ }^{3}$ The marginal tax rate is calculated by adding the employee's portion of Social Security taxes (approximately 12 percent), income tax (the lowest rate is 10 percent), and local taxes (the lowest rate is 5 percent), after taking into account deductions for Social Security contributions and for employment income. This calculation is based on the tax code in 2006, without reflecting the temporary tax cut.

${ }^{4}$ Means-tested transfers with discontinuous jumps under a static budget constraint are also found in other settings. Medicaid in the United States, for example, creates a budget constraint with the "Medicaid notch" (Gruber 2000). In Japan, the public pension benefit of the working elderly used to be cut discretely when earnings exceeded a certain threshold, although such features were eliminated in several steps from 1989 to 2005 (Abe 2001, Ohtake and Yamaga 2004). 
empirical evidence on how these rules affect labor supply of married women. Section 3 presents a dynamic labor supply model, examines the properties of optimal labor supply choices, and discusses the implications of these choices on the welfare cost. Section 4 illustrates the results of Section 3 with a numerical example. Section 5 concludes.

\section{Tax, Social Security Systems, and Stylized Facts}

In this section, aspects of the income tax and Social Security systems concerning the labor supply of married women are briefly explained. ${ }^{5}$ In Japan, Social Security enrollment rules and firm benefit policies create work disincentives for married women. In addition, two sets of empirical evidence are presented as background to the subsequent analysis.

\subsection{Tax and Social Security Systems}

The social insurance participation rules relevant to low-income married women are as follows: when the wife's earnings are below 1.3 million yen per year, she is eligible to receive Social Security and healthcare benefits as a dependent of her salaried husband. Therefore, when a wife works part-time and earns less than 1.3 million yen, she does not have to pay Social Security contributions out of her income, yet is eligible to receive benefits through her husband's coverage. When a part-time employee works more than 30 hours per week, on the other hand, the employer is required to enroll her in the Employees' Pension Program and provide health insurance. To avoid paying for social insurance contributions (payments

\footnotetext{
${ }^{5}$ Detailed and thorough explanations of the tax and Social Security systems and their effect on the labor supply of married women in Japan can be found in Yamada (2004), Nagase and Nawata (2005), Akabayashi (2006), and Sakata and McKenzie (2006), among others.
} 
into a public pension, and premiums for health and unemployment insurance), the wife has reason to limit her hours of work.

Furthermore, as long as the wife's earnings are less than or equal to 1.03 million yen per year, the husband's employer in many cases provides an allowance for the spouse as one of the husband's fringe benefits. Since this allowance is usually completely cut off if the wife's earnings exceed the threshold, it is quite likely to create work disincentive effects in the wife's labor supply. The income tax system also creates kinks in a family's budget constraint for the wife's income levels between 1.03 million yen and 1.65 million yen annually.

Tax Reform in 2004 changed the budget constraint for the portion of the wife's earnings are between 0 and 1.03 million yen, while it is unchanged for the wife's earnings above 1.03 million yen. This reform means that the Exemption for Spouse and Special Exemption for Spouse that the husband can claim are less generous than before. This change shifts the budget constraint of the household downward for the portion of the wife's earnings up to 1.03 million yen, because the tax liability of the husband increases. The size of the increase in the annual tax burden is 380,000 yen times the husband's marginal tax rate at most, which is not large: assuming that the husband's marginal tax rate is 30 percent, the decline in disposable income is 114,000 yen (about 1,100 US dollars) per year. The fact that the budget constraint has dips for the wife's annual earnings of 1.03 million yen and 1.3 million yen was not changed by this reform. Thus, the reform essentially operates as income effect. Sakata and McKenzie (2006) examine whether there were behavioral responses to this policy change in 2004 using a panel data set and find that labor supply responses by wives were small.

A typical budget constraint for married women who intend to work on a part- 
time basis is shown in Figure 1a under the tax code in 2006 (without incorporating the temporary tax cut). For married women, the marginal tax rate for earnings between 1.03 million yen and 1.41 million yen is quite high. Furthermore, sizable lump-sum Social Security contributions start at an income of 1.3 million yen or at work of 30 hours per week. Note that the marginal tax rate falls rather substantially for earnings over 1.41 million yen. Thus, although a wife earning between 1.03 million and 1.41 million yen is severely penalized, once her earnings exceed 1.41 million the marginal penalty for work diminishes.

The 1.03 million yen ceiling is most relevant for married, female part-time employees with salaried husbands. Full-time female employees usually earn much more than 1.03 million yen, so for them this ceiling is irrelevant. It is also likely to be irrelevant for self-employed workers and family workers (those who work in a family-operated enterprise or a family farm); self-employed income is taxed differently from wages and salaries, and family workers are less likely to be married to salaried husbands.

\subsection{Concentration of Earnings around 1.03 million yen}

As explained above, the static budget constraint for married women who work part-time has a discontinuous dip at annual earnings of 1.03 million yen. With such a budget constraint, it is expected that this group of workers has reason to constrain their hours of work so that the earnings remain at 1.03 million yen or less.

Figure 2 displays the earnings distribution of married women working as parttime employees from the micro data of the National Survey of Family Income and Expenditure (NSFIE) in 2004 (Statistics Bureau, Ministry of Public Management, 
Home Affairs, Posts and Telecommunications). The sample consists of women married to male household heads. The distributions are drawn separately for samples of wives aged 30-39, 40-49, and 50-59. The earnings figures are the annual earnings in the previous year (2003). ${ }^{6}$ Figure 2 shows that there is a heavy concentration of earnings around 1.03 million yen, suggesting that the ceiling is a binding constraint in determining part-time labor supply of married women. The concentration is particularly significant for older women.

\subsection{Continuity of Participation in Part-time Work}

Next, I present evidence on participation patterns in part-time work by married women by cohort. Figure 3 illustrates the cohort experiences of participation in part-time work by using three cross sections (years 1992,1997, and 2002) from the Employment Status Surveys (the Ministry of Public Management, Home Affairs, Posts and Telecommunications of Japan). ${ }^{7}$ Specifically, the ratios of the number of part-time employees to population (called the part-time employment ratio in the following) are calculated for married women, separately for by education and age (5-year interval). In Figure 3, the part-time employment ratios are plotted against age for various cohorts of married women. Here, I focus on senior high school graduates and junior college graduates, for whom part-time work is most prevalent.

There are significant cohort differences in the likelihood of participating in

\footnotetext{
${ }^{6}$ Abe (2003) reports on earnings distributions of married and single women who work parttime in 1989 and 1994 using the data from General Survey of Part-time Workers' Conditions. There is a heavy concentration around 1.03 million yen for married women; such a concentration is not observed for single women, who are not eligible for the benefits that married women receive. Akabayashi (2006) also presents a similar distribution for married women working part-time.

${ }^{7} \mathrm{~A}$ detailed description of women's labor force experiences using the repeated cross sectional data of the Employment Status Surveys is found in Abe (2008).
} 
part-time employment. Later cohorts of married women are more likely to work as part-time employees than earlier cohorts are. The figures show that entry into part-time work by married women occurs between the ages of 30 and 45 , when the part-time profiles exhibit steep increases. For cohorts born between 1958 and 1962, for example, the part-time employment ratio increased by approximately 20 percent from 1992 (when the age of this cohort was 30-34) to 2002 (age 40-44). It is also notable that the part-time employment ratio does not decline with age until around age 60. Based on this evidence, I formulate the model in Section 3 in a way that a married woman chooses her work schedule over a period of 25 years, from an age of approximately 35 to 60 . The cohort differences in the part-time employment ratios may be understood as later cohorts reenter part-time work at a younger age than the earlier cohorts did. However, it is still true that significant reentry into part-time work occurs at ages in the late 30 s and early 40s, especially for junior college graduate women. The pattern in Figure 3 also suggests that part-time workers have a strong attachment to work. ${ }^{8}$ It highlights the importance of considering dynamic aspects (such as continuation in part-time employment or timing of retirement) in understanding labor supply of female parttime workers. In the rest of the paper, I confine attention to the behavioral and efficiency consequences of the 1.03 million yen ceiling in a dynamic labor supply model.

\footnotetext{
${ }^{8}$ Since the data used here are repeated cross sections, reentry (retirement) is measured by the net increase (decrease) in participation within each cohort. It may accompany an increase in participation for some and an increase in exit by others. Therefore, it is not necessarily reentry (retirement) in the usual sense.
} 


\section{Dynamic Labor Supply Model}

In this section, I present a simple dynamic model of labor supply in order to assess the behavioral consequences of the 1.03 million yen ceiling. The main differences between this framework and other research are endogenous retirement and consumption smoothing. The importance of consumption smoothing in analyzing labor supply has previously been pointed out in the literature on intertemporal labor supply (e.g. MaCurdy 1981, Altonji 1986, Blundell and MaCurdy 1999). The model here differs from the standard intertemporal labor supply model, in that the means-tested transfer introduces discontinuities in the budget constraint. Previous studies that consider nonlinear budget sets in a dynamic model includes Heckman et al. (2003) and Sefton et al. (2005). Heckman et al. (2003) have incorporated nonconvexities created by the United States' Earned Income Tax Credit (EITC) into a dynamic model of labor supply and skill formation. Sefton et al. (2005) use a simulation model of retirement behavior with the means-tested transfer system in assessing the impact of the transfer systems in the UK and Denmark.

\subsection{Model}

I use a simple dynamic labor supply model, in which a worker retires because the value of her leisure increases with age. The utility is additively separable over time, and the worker maximizes the present discounted value of the utility function. For simplicity, it is assumed that the woman makes decisions from $A G E_{0}$ to $A G E_{0}+T$. The time period is denoted as the woman's age minus $A G E_{0}$, and thus runs from year 0 to year $T$ where $T$ is fixed and exogenous. $T$ is set to 24 (so the total number of time periods is 25 ), because this model is especially concerned with the retirement behavior of women who enter the workforce in their late $30 \mathrm{~s}$ 
or 40s. The household maximizes the following utility function:

$$
\sum_{t=0}^{T} u\left(C_{t}, \bar{L}-h_{t}, t\right)=\sum_{t=0}^{T} \rho^{t}\left\{\phi\left(C_{t}\right)+\alpha_{t} v\left(\bar{L}-h_{t}\right)\right\},
$$

where $t$ is the year index, $C_{t}$ is the household consumption in year $t, \bar{L}$ is the annual time endowment, $h_{t}$ is the number of hours worked in year $t$, and $\rho$ is the rate of time preference. $\bar{L}$ is assumed to be fixed over time. The one-period utility depends on consumption and the wife's leisure time $\left(\bar{L}-h_{t}\right)$. The functions $\phi$ and $v$ are assumed to be increasing and concave. The term $\alpha_{t}$ increases with the worker's age, reflecting the increasing value of leisure with age. ${ }^{9}$ With this utility function, retirement occurs because the (marginal) disutility of work increases with age. Note that consumption and leisure are separable within period.

The budget constraint is

$$
A_{0}+\sum_{t=0}^{T} \frac{w_{t} h_{t}+T R F_{t}-C_{t}}{(1+r)^{t}}=0
$$

where $A_{0}$ is the initial asset level, $w_{t}$ is the wife's hourly wage in period $t, T R F_{t}$ is the transfer payment received by the household in period $t$, and $r$ is the interest rate at which the household borrows and saves.

It has been implicitly assumed that the husband's labor supply is unaffected by the wife's labor supply, so the discounted sum of the husband's earnings is included in $A_{0}$. For simplicity, it is also assumed that $\rho=1 /(1+r)$.

The term $T R F_{t}$ is determined as follows:

$$
T R F_{t}= \begin{cases}T R F & \text { if } w_{t} h_{t} \leq \theta \\ 0 & \text { otherwise }\end{cases}
$$

\footnotetext{
${ }^{9} \mathrm{~A}$ similar assumption is used in Burtless and Moffitt (1985) and Gustman and Steinmeier (1986).
} 
where $\theta$ is the threshold value of the wife's earnings. The household receives transfer benefits with a value of $T R F$ in year $t$, as long as the wife's earnings are less than or equal to the threshold $\theta$. This includes the case where she does not work at all. When her earnings exceed the threshold value, the household becomes ineligible for the transfer payment. This is the simplest form of meanstested transfer. In the present context, the transfer benefits represent the spousal allowance given by the husband's employer and the value of Social Security contributions from which the wife is exempted as a low-income dependent of her salaried husband. ${ }^{10}$ This model abstracts the main features of the Japanese Social Security system and the fringe benefit policies of many firms, as explained in Section 2. The static budget constraint thus dips at the point at which the wife's earnings exceed the threshold, because the wife (or household) loses a fixed sum of benefits at that point. The budget constraint is therefore nonlinear and non-convex. Figure $1 \mathrm{~b}$ shows the simplified single-period budget constraint from equation (3). This simplification is primarily motivated by the fact that the 1.03 million yen ceiling seems to influence labor supply choices much more significantly than any other non-linearities and non-convexities in the budget constraint, as can be observed from the earnings distributions in Figure 2.

Since retirement is one of the principal interests of this analysis, the following constraint is also imposed:

$$
h_{t} \geq 0 \text {. }
$$

It is assumed that the wife chooses her hours of work in each period to maximize

\footnotetext{
${ }^{10}$ This assumption means that the wife continues to receive benefits after her retirement, which may not be entirely consistent with reality in the following sense. If the husband is older than the wife, he is likely to retire from his career job sometime around the wife's retirement. When he retires, he stops receiving an allowance for spouse from his employer. In addition, when the husband is not working, the wife is much less likely to be covered by the husband's public pension and health insurance.
} 
the household's dynamic utility under perfect foresight. The model is solved to find the optimal labor supply choices of the wife $\left(h_{t}, t=0,1, \cdots, T\right)$ and the household's consumption $\left(C_{t}, t=0,1, \cdots, T\right)$. The wife's optimal labor supply determines whether transfer benefits are received in each period.

This model differs from many other intertemporal labor supply models in the following two ways. First, due to the means-tested transfer, the static budget constraint has a discrete dip at the earnings threshold. This is similar to introducing a fixed cost of work, except that in this case the dip is located at a positive number of working hours instead of at the point of zero hours (the work vs. no-work margin). Second, in many dynamic models of retirement behavior the choice of working hours is modeled as a discrete variable (e.g. Rust and Phelan 1997, Sefton et al. 2005). The choice of a discrete specification is not very attractive here, because I wish to model the behavior of setting earnings very close or equal to the threshold $(\theta)$. This feature cannot be captured by imposing a discrete choice of hours. Furthermore, part-time workers in Japan have more flexibility in their choice of working hours than regular workers do, which makes it reasonable to model working hours as a continuous variable.

\subsection{Value Function and Conditions for the Optimum}

In this subsection, I present the conditions for an optimal labor supply choice when the household faces a means-tested transfer scheme as explained above.

Let $V\left[A_{t}, t\right]$ be the value function for this dynamic optimization problem. Given the utility function, the budget constraint, and the transfer scheme, this function can be expressed as:

$$
V\left[A_{t}, t\right]=u\left(C_{t}, \bar{L}-h_{t}, t\right)+\rho V\left[(1+r)\left\{A_{t}+w_{t} h_{t}+T R F \cdot I\left(w_{t} h_{t} \leq \theta_{t}\right)-C_{t}\right\}, t+1\right],
$$


where $I\left(w_{t} h_{t} \leq \theta\right)$ is an indicator function that takes the value 1 if the wife's earnings do not exceed the threshold and zero otherwise.

In order to derive the optimum, the value function (5) is maximized subject to constraints (3) and (4). To do so, form the Lagrangian as follows:

$$
\begin{array}{r}
L=u\left(C_{t}, \bar{L}-h_{t}, t\right)+\rho V\left[(1+r)\left\{A_{t}+w_{t} h_{t}+T R F \cdot I\left(w_{t} h_{t} \leq \theta\right)-C_{t}\right\}, t+1\right] \\
+\mu_{1 t}\left(\frac{\theta}{w_{t}}-h_{t}\right)+\mu_{2 t} h_{t},
\end{array}
$$

where $\mu_{1 t}$ is a multiplier for the constraint of receiving benefits in period $t$ and $\mu_{2 t}$ is a multiplier for the zero-hour constraint in period $t$. Maximization is performed for two possible outcome in each period: one for the case of receiving benefits in period $t$, and the other for the case of not receiving benefits in period $t$. The firstorder conditions for maximizing $V$ conditional on receiving benefits in period $t$ are:

$$
\begin{gathered}
\frac{\partial L}{\partial C_{t}}=u_{C}-\rho \cdot(1+r) \cdot V_{A}=0, \\
\frac{\partial L}{\partial h_{t}}=-u_{L}+\rho \cdot(1+r) \cdot V_{A} \cdot w_{t}-\mu_{1 t}+\mu_{2 t}=0 .
\end{gathered}
$$

Since the constraints $\theta / w_{t}-h_{t}=0$ and $h_{t}=0$ can never be satisfied simultaneously, there are now only three cases to consider: (a) the threshold is binding $\left(\mu_{1 t}>0\right)$; (b) the wife does not work $\left(\mu_{2 t}>0\right)$; or (c) an interior solution for hours $\left(\mu_{1 t}\right.$ $=\mu_{2 t}=0$ ). The first-order conditions for the case of not receiving benefits are similar to those for the interior solution.

The $V_{A}$ term in the first-order conditions given above represents the marginal value of household assets. Because $\rho=1 /(1+r), V_{A}\left[A_{t}, t\right]=V_{A}\left[A_{0}, 0\right]$. Following the previous literature, I denote $V_{A}$ as $\lambda$ throughout the rest of this paper. Note that 
the first order conditions are expressed in terms of $u_{L}, u_{c}, \lambda$, and $w_{t}$.

\subsection{Characteristics of Labor Supply Behavior}

In this subsection, properties of the working hours profile $\left(h_{t}, t=0,1, \cdots, T\right)$ are examined under the above model. To understand the effects of the means-tested transfer, I compare the allocation in this case to those attained under other settings. The case where the household optimizes under a means-tested transfer is called the "means-tested transfer" (MTT) regime. The hypothetical case where no such transfer system exists is referred to as the "no-transfer" regime.

The means-tested transfer affects labor supply choices in three different ways. First, the wealth effect of the transfer reduces both hours of work and years of work. ${ }^{11}$ Second, the discrete nature of the means test encourages the wife to set her earnings exactly equal to the threshold during some periods, in order to receive benefits. This effect also reduces the wife's hours of work and/or the number of years she works. Note that both of these effects are also present in most static labor supply models. The third effect, which is not found in a static framework, is a spillover effect of the transfer on labor supply in years when the threshold is not binding. Under the MTT regime, working hours in those years (i.e., the years when $w_{t} h_{t}<\theta$ or $w_{t} h_{t}>\theta$ ) tend to be long in the sense explained below. An intuitive explanation of this result is that, to partially compensate for the reduction of her labor supply (i.e., the first two effects) in binding years, the wife works longer hours in those years when the threshold is not binding.

To understand the full impact of the transfer system, it is useful to separate out the wealth effect it creates. To do so, let $P D V \_T R F$ be the present discounted

\footnotetext{
${ }^{11}$ In a static model, this effect is referred to as the "income effect." I call it the "wealth effect" because of the model's dynamic nature.
} 
value of all transfer payments received by a household at its optimal labor supply choice under the MTT regime. ${ }^{12}$ Next, find the labor supply and consumption schedules when initial assets are equal to $A_{0}+P D V \_T R F$ and the transfer system does not exist. This is equivalent to giving a household all the benefits as a single lump-sum payment, which it can then spend as it wishes. This allocation will be referred to as the "lump-sum transfer"(LST) case. The following analysis compares allocations in the MTT regime and the LST case. Let $\lambda_{M T T}$ and $\lambda_{L S T}$ refer to the marginal utility of assets under the MTT regime and the LST case respectively. Similarly, let the working hours schedule in the LST case be $h_{t}^{L S T}$ $(t=0,1, \cdots, T)$ and that in the MTT regime be $h_{t}^{M T T}(t=0,1, \cdots, T)$. Since the wealth effect created by the means-tested transfer is accounted for under the LST allocation, this leads to the following proposition:

Proposition 1. If there is at least one period when the constraint $w_{t} h_{t}=\theta$ is binding, then:

$$
\lambda_{M T T}>\lambda_{L S T}
$$

Proof. Suppose the claimed inequality does not hold, so that $\lambda_{M T T} \leq \lambda_{L S T}$. The first-order conditions for the optimal choice of hours in the MTT regime and the LST case are given as follows:

$$
\begin{array}{rr}
u_{L}=w_{t} \lambda_{M T T}-\mu_{1 t} & \text { MTT case } \\
u_{L}=w_{t} \lambda_{L S T} . & \text { LST case }
\end{array}
$$

Given that $\lambda_{M T T} \leq \lambda_{L S T}$ and $\mu_{1 t}>0$ for at least one $t, w_{t} \lambda_{M T T}-\mu_{1 t} \leq w_{t} \lambda_{L S T}$ for all $t$, and this inequality is strict for $t$ for which $\mu_{1 t}>0$ holds. Given the separability of leisure and consumption and the concavity of the utility function,

\footnotetext{
${ }^{12}$ Note that the value of $P D V_{-} T R F$ depends on the labor supply choices of the wife.
} 
the assumed inequality implies that $h_{t}^{M T T} \leq h_{t}^{L S T}$ for all $t$, and that this inequality is strict for some $t$. Using this, the following relationship holds:

$$
A_{0}+\sum_{t=0}^{T} \frac{w_{t} h_{t}^{M T T}}{(1+r)^{t}}+P D V \_T R F<A_{0}+\sum_{t=0}^{T} \frac{w_{t} h_{t}^{L S T}}{(1+r)^{t}}+P D V \_T R F
$$

Because of non-satiation, the present discounted value of consumption under the MTT regime is equal to the LHS of equation (11). Similarly, the same value under the LST case is given by the RHS of (11). Therefore,

$$
\sum_{t=0}^{T} \frac{C_{t}^{M T T}}{(1+r)^{t}}<\sum_{t=0}^{T} \frac{C_{t}^{L S T}}{(1+r)^{t}}
$$

On the other hand, if $\lambda_{M T T} \leq \lambda_{L S T}$, the first-order condition for consumption and the concavity of $u$ imply that $C_{t}^{M T T} \geq C_{t}^{L S T}$ for all $t$. This contradicts equation (12).

Proposition 1 states that the marginal utility of assets under the MTT regime $\left(\lambda_{M T T}\right)$ is greater than that under the LST case $\left(\lambda_{L S T}\right)$, reflecting the fact that the means-tested transfer creates distortions in labor supply. Since the resources provided exogenously are the same in both cases, distortions must arise from the way in which transfer payment is provided (i.e., means-tested or lump sum). Proposition 1 implies the following:

Corollary 1 (Spillover Effect). Suppose hours worked in period t are determined as an interior solution. Then, during those years,

$$
h_{t}^{L S T}<h_{t}^{M T T}
$$

This follows directly from a standard comparative static result on the first- 
order condition for the interior optimum (equation (8) and the similar equation for the LST case).

Corollary 1 is understood as the "spillover effect" of the ceiling. Under the MTT regime, the wife supplies more hours than she would under the LST case during those periods when her annual earnings are not set equal to the threshold. In the context of retirement, Corollary 1 implies that hours in years just before retirement tend to be longer under the MTT regime than under the LST case. Because the parameter $\alpha_{t}$ in the utility function (the coefficient attached to leisure) increases with age, working hours decline as the wife ages. After a certain point, the ceiling is no longer binding because the unconstrained hours do not yield earnings that exceed the threshold. During those periods the wife tends to supply more labor than she would in the absence of the means-tested transfer, after controlling for the wealth effect. Note that this effect has its source in $\lambda$ : the threshold makes the wife earn less during constrained periods (the years when the threshold is binding), which increases the value of $\lambda$ (Proposition 1). This in turn increases working hours under the MTT regime during periods when the threshold is not binding. The spillover effect may also exist in early periods. When $t$ is small and $\alpha_{t}$ is small, the wife may choose to supply enough hours for her earnings to exceed the threshold. Once again, working hours during such periods are longer under the MTT regime than under the LST case. ${ }^{13}$

\footnotetext{
${ }^{13}$ It can be shown that, if there is at least one year when the earnings are equal to $\theta$ under the MTT regime, the present discounted value of the wife's earnings from period 0 to period $T$ under the MTT regime are less than those under the LST case. While the spillover effect in Corollary 1 partially compensates the lost earnings in constrained years by a greater labor supply in unconstrained years, the compensation is not "full": the wife's lifetime earnings are depressed because of the means-tested transfer.
} 


\subsection{Life Cycle Welfare Cost of the Ceiling}

In the literature on nonlinear budget sets, welfare levels under different tax regimes are compared by using the expenditure function. Here I apply the same method in a dynamic context, following Auerbach and Kotlikoff (1987). ${ }^{14}$

Let $U_{M T T}$ be the present discounted value of the utility function under the MTT regime, $U_{L S T}$ be that under the LST case, and $U_{N T}$ be that under the notransfer regime. Let $A_{0}(U)$ be a function giving the value of initial assets that yield dynamic utility $U$ when the transfer is absent. $A_{0}(U)$ is obtained by solving the problem of expenditure minimization in the absence of the transfer, subject to the constraint that the allocation's dynamic utility is $U$.

Let $\tilde{C}_{t}(\lambda(U))$ and $\tilde{h}_{t}(\lambda(U))$ be the consumption and hours schedules that solve the minimization problem. Here $\tilde{C}_{t}$ and $\tilde{h}_{t}$ are written as functions of $\lambda$, to simplify subsequent analysis. ${ }^{15}$

Let $D W L$ be the lifetime welfare cost (i.e., dynamic deadweight loss) of the ceiling. This is defined as the present discounted value of the transfer payment minus the monetary value of the utility gain from a transfer to the household. Since the utility of the household changes from $U_{N T}$ to $U_{M T T}$ when there is a transfer, the monetary equivalent of the utility gain is given by $A_{0}\left(U_{M T T}\right)-A_{0}\left(U_{N T}\right)$. Thus $D W L$ is

$$
D W L=P D V \_T R F-\left\{A_{0}\left(U_{M T T}\right)-A_{0}\left(U_{N T}\right)\right\} .
$$

\footnotetext{
${ }^{14} \mathrm{~A}$ recent example of research using the expenditure function in a static context is the study by Friedberg (2000). The relationship between the dynamic welfare cost and the per-period welfare cost has been examined by Blackorby et al. (1984) and Keen (1990).

${ }^{15}$ In fact, the dynamic utility level $U$ is not written explicitly in the following.
} 
Equation (13) can then be rewritten as:

$$
\begin{aligned}
D W L & =P D V_{-} T R F-\left\{A_{0}\left(U_{M T T}\right)-A_{0}\left(U_{L S T}\right)\right\}-\left\{A_{0}\left(U_{L S T}\right)-A_{0}\left(U_{N T}\right)\right\} \\
& =A_{0}\left(U_{L S T}\right)-A_{0}\left(U_{M T T}\right) .
\end{aligned}
$$

The second line in equation (14) follows because, by definition, $A_{0}\left(U_{L S T}\right)-A_{0}\left(U_{N T}\right)$ is equal to $P D V_{-} T R F$; in the LST case, an amount equal to $P D V \_T R F$ is given to the household as a lump-sum payment. As equation (14) shows, the dynamic welfare cost is given by the difference between the initial asset level that yields utility $U_{L S T}$ and the initial asset level that yields utility $U_{M T T}$, when the budget constraint does not have any distortionary features.

The dynamic welfare cost in equation (14) can be approximated as a sum over per-period terms using $\tilde{C}_{t}(\lambda)$ and $\tilde{h}_{t}(\lambda)$. This point is summarized in the following proposition:

Proposition 2. Let $\lambda_{M T T}^{\tilde{M}}$ be the value of $\lambda$ corresponding to the allocation that yields utility $U_{M T T}$, in the absence of the transfer. Let $\Delta \lambda=\lambda_{M T T}-\lambda_{L S T}$. Define $\tilde{C}_{t}^{\prime}$ as the derivative of $\tilde{C}_{t}(\lambda)$ with respect to $\lambda$, and define ${\tilde{h_{t}^{\prime}}}_{\text {as }}$

$$
h_{t}^{\prime} \tilde{(\lambda)}=\left\{\begin{array}{ll}
\lim _{\varepsilon \rightarrow+0} \frac{\tilde{h}_{t}(\lambda+\varepsilon)-\tilde{h}_{t}(\lambda)}{\varepsilon} & \text { if } \tilde{h}_{t}>0 \\
0 & \text { if } \tilde{h}_{t}=0
\end{array} .\right.
$$

That is, $\tilde{h}_{t}^{\prime}$ is the right-hand derivative of $h$ with respect to $\lambda$ for positive hours, and is zero when the wife does not work. Then DWL can be approximated as follows:

$$
D W L \cong \sum_{t=0}^{T} \frac{\left\{\tilde{C}_{t}^{\prime}\left(\lambda_{L S T}\right)-w_{t} \tilde{h}_{t}^{\prime}\left(\lambda_{L S T}\right)\right\} \triangle \lambda}{(1+r)^{t}} .
$$


Proof. Using the definitions of $\tilde{C}_{t}(\lambda)$ and $\tilde{h}_{t}(\lambda)$, equation (14) can be rewritten as

$$
\sum_{t=0}^{T} \frac{\left[\tilde{C}_{t}\left(\lambda_{L S T}\right)-w_{t} \tilde{h}_{t}\left(\lambda_{L S T}\right)\right]-\left[\tilde{C}_{t}\left(\lambda_{M T T}\right)-w_{t} \tilde{h}_{t}\left(\lambda_{M T T}\right)\right]}{(1+r)^{t}}
$$

Equation (16) is then obtained by taking a linear approximation of equation (17) with respect to $\lambda$.

Equation (16) states that the dynamic deadweight loss is the discounted sum of per-period terms. The change in expenditure (i.e., $\left.\tilde{C}_{t}-w_{t} \tilde{h}_{t}\right)$ caused by the "change" in $\lambda(\Delta \lambda)$ is what contributes to deadweight loss in period $t .{ }^{16}$

Notice that for periods when $\tilde{h}_{t}\left(\lambda_{M T T}\right)=0, \tilde{h}_{t}^{\prime}$ becomes zero, so the term involving $\tilde{h_{t}^{\prime}}$ only affects $D W L$ during years with positive $\tilde{h_{t}}$. Thus, distortions from hours choices arise only from years with positive $\tilde{h}_{t}$. Changes in the consumption $\left(\tilde{C}_{t}^{\prime} \Delta \lambda /(1+r)^{t}\right)$ create distortions in all periods, including years for which $\tilde{h}_{t}=0$. Furthermore, decomposition into within-period terms according to equation (16) is obtained by the derivatives of $\tilde{C}_{t}$ and $\tilde{h}_{t}$, and not by analyzing the expenditures for the allocation derived under the MTT regime $\left(C_{t}^{M T T}\right.$ or $\left.h_{t}^{M T T}\right)$. This fact is not usually taken into account in static labor supply models that analyze the welfare cost of the ceiling. Unless appropriate care is taken with the changes in consumption and hours due to $\Delta \lambda$ and the timing of retirement, the deadweight loss calculated in a static framework will not correspond to the time $t$ component of $D W L$ (i.e., $\left.\left.\left(\tilde{C}_{t}^{\prime}-w_{t} \tilde{h}_{t}^{\prime}\right) \triangle \lambda\right) /(1+r)^{t}\right)$.

\footnotetext{
${ }^{16}$ Note that $\Delta \lambda$ is $\lambda_{M T T}-\lambda_{L S T}$, and not $\lambda_{M T T}-\lambda_{L S T}$. It can be shown that $\lambda_{M T T} \geq \lambda_{M T T} \geq \lambda_{L S T}$, so $\Delta \lambda$ is always positive. $\left(\tilde{C}_{t}^{\prime}-w_{t} \tilde{h}_{t}^{\prime}\right)$ is the derivative of the period $t$ expenditure function with respect to $\lambda$.
} 


\section{Illustration: A Numerical Example}

In this section, I present a numerical example to illustrate the properties of labor supply patterns under the model presented above, and the welfare cost of the ceiling. The model is solved numerically using an algorithm that is explained in the Appendix.

\subsection{Utility Function and Parameter Values for the Example}

Assume that the utility function has the following form:

$$
\sum_{t=0}^{T} \rho^{t} u\left(C_{t}, \bar{L}-h_{t}, t\right)=\sum_{t=0}^{T} \rho^{t}\left\{\ln \left(C_{t}\right)+\alpha_{t} \ln \left(\bar{L}-h_{t}\right)\right\} .
$$

In this example, the parameters of the model are set as follows. ${ }^{17}$ For $\alpha_{0}$ (the coefficient attached to leisure at the initial period) I use a value of 0.85 . This corresponds to a value of 0.46 in the Stone-Geary type utility function, where the coefficients attached to the log of consumption and the log of leisure time add up to $1 .{ }^{18}$ It is assumed that $\alpha_{t}$ increases with age, according to the function $\alpha_{t}=\alpha_{0} \exp (0.05 t)$. The annual time endowment is taken to be 4000 hours. ${ }^{19}$ The hourly wage is set to 850 yen, which is a typical rate for female part-time workers in Japan. The value of the transfer payment $(T R F)$ is set to 210,000 yen per year,

\footnotetext{
${ }^{17}$ Although it is desirable to fit the model to empirical data and use the estimated utility function parameters in the numerical example, such an attempt is not made in this paper. Fitting the model to data requires a panel data set that covers a reasonably long period, including the ages around retirement. Such a data set for Japanese women is unavailable at the time of writing. Empirical investigation is left for future research.

${ }^{18}$ Hoynes (1996) estimates the parameter attached to the wife's leisure time as 0.46 in the StoneGeary utility function based on a static labor supply model, using a sample of low-income couples in the Panel Study of Income Dynamics (PSID). Hyslop (2001) provides estimates of this parameter ranging from 0.36 to 0.42 based on a dynamic model using a sample of continuously married couples in the PSID.

${ }^{19}$ This parameter is set to 8736 hours per year in Browning et al. (1985), and to 90 hours per week (4680 hours per year) in Blundell and Walker (1986).
} 
and the threshold value $(\theta)$ is set to 1.03 million yen. ${ }^{20}$ The initial asset value $\left(A_{0}\right)$ is allowed to range from 8 million yen to 20 million yen. The hourly wage, the transfer amount, and the threshold value are assumed to be fixed over all periods, to keep the analysis simple and make the properties of the model as transparent as possible. The parameter values are summarized in Table 1 . While only typical labor supply schedules are presented in the following subsections, the model is solved for a range of initial asset levels.

\subsection{Hours Profile and Welfare Cost}

Figure 4-1 shows the labor supply schedule for an initial asset value $\left(A_{0}\right)$ of 9 million yen under the MTT regime (thick line with circular points), under the no-transfer regime (dotted line), and in the case of the LST case (thick line with square points). The vertical axis is the wife's annual working hours, and the horizontal axis is $t$ (the wife's age minus $A G E_{0}$ ). All the essential properties of the optimal work schedule, as discussed in the previous section, can be seen in this figure. First, due to the wealth effect of the transfer, hours under the no-transfer regime are longer than those in the LST case. Under the no-transfer regime, the wife tends to work longer hours and for more periods than she would under the MTT regime. Second, as the flat portion of the MTT regime schedule shows, the wife sets her earnings equal to the threshold for ten years (from year 3 to year 12). Third, the number of hours worked in unconstrained years (years 0-2 and 13-20 in Figure 4-1) is greater under the MTT regime than in the LST case. This is due to

\footnotetext{
${ }^{20}$ The transfer amount is roughly equal to the workers' portion of the minimum Employees' Pension contribution, plus the average spousal allowance provided by employers. The value of 210,000 yen adopted in this model should be understood as a lower bound of $T R F$. As for the threshold, its actual value has changed several times: 0.9 million yen from 1984 to 1988,1 million yen from 1989 to 1994, and 1.03 million yen from 1995 to 2005 . The income limit for social insurance contributions has also been revised several times during the same period.
} 
the spillover effect explained in Corollary 1: in the presence of the means-tested transfer, the wife supplies fewer hours in the interim periods (years 3-12 in Figure 4-1) but more hours in unconstrained periods (years 0-2 and years 13-20). This behavior translates to a delay in retirement. In the years close to retirement the threshold is no longer binding, so Corollary 1 is applicable. The means-tested transfer discourages labor supply for a limited time, but in a model with endogenous retirement the wife responds by staying in the labor market for longer than she would otherwise.

Figure 4-2 displays hours schedules for an initial asset level of 17 million yen. In this case the wife does not work long hours (about 2000 hours per year) in the early years (low values of $t$ ). The three features described above can also be seen in this figure.

Detailed statistics and the properties of the optimal labor supply schedules are given in Table 2. The first row is the total number of years worked. The wife retires later under the MTT regime than under the LST case. When $A_{0}$ is 9 million yen, the wife retires in year 20 under the MTT Regime, while she does so in year 19 under the LST case, so retirement is delayed by 1 year by the means-tested transfer. For $A_{0}$ of 17 million yen, it is delayed by 2 years in the same sense. Row 2 displays the number of years with positive hours and annual earnings below the threshold. With an initial asset level of 9 million yen, if the transfer is nonexistent then the wife spends only 8 years with such earnings (i.e., working and earning less than $\theta$ ). Under the MTT regime, on the other hand, 17 out of 20 working years are spent with earnings below the threshold. It therefore follows that under the MTT regime, married, part-time female workers usually set their hours equal to the threshold, just as predicted in static models. Row 3 provides the wife's 
total number of working hours (summed over all 25 years, without discounting hours worked at different points in time). For the cases considered here, this number is less under the MTT regime than under the LST case, by 9 to 15 percent. The transfer system thus reduces working hours overall, even though the spillover effect described in Corollary 1 partially offsets work disincentive effects.

The magnitude of the spillover effect can be seen in rows 4 and 5. Row 4 lists the total number of hours worked in the unconstrained early years, when the wife is young and the value of her leisure is low, and the threshold is not binding. The time period indices for the unconstrained early years are listed in square brackets in the first line of row 4 . The second line of row 4 gives the total number of undiscounted hours worked in these years. When $A_{0}$ is equal to 9 million yen, the first 3 years (years 0-2) are unconstrained and a total of 7216 hours are worked during this interval. This number is 4.6 percent greater than the total number of hours worked in the first three years under the LST case. When $A_{0}$ is 17 million yen, however, there are no unconstrained early years due to the high initial assets.

The magnitude of spillover effects is even greater in the unconstrained years just before full retirement. These effects are shown in row 5 of Table 2, in the same manner as row 4 . When $A_{0}$ is equal to 9 million yen, the last 7 years of working life are unconstrained years with earnings less than $\theta$. The total number of working hours in these 7 years ( years 13-19) is 4272, while in the lump-sum transfer case the total number of hours supplied during this interval is 2865 . The spillover effect therefore boosts the number of hours worked before retirement by 49 percent. For $A_{0}$ of 17 million yen, the hours in unconstrained years just before retirement increase by 51 percent. In this example, one can see that the magnitude of the spillover effect is sometimes large. 


\subsection{Welfare Cost of the Ceiling}

Rows 6 through 8 of Table 2 give figures related to the effect of the means-tested transfer on efficiency. The present discounted sum of the transfer payment is shown in row 6. It is 3.56 million yen for the initial assets of 9 million yen, and 4.18 million yen for the initial assets of 17 million yen. In this example, the value of the transfer generally rises as the initial assets of the household increase, so the transfer scheme is regressive. Here, the wives in households with a high level of initial assets supply less part-time labor and are more likely to collect benefits. This is consistent with the concern raised by Oishi (2003) in a discussion of distributional consequences of the 1.03 million yen ceiling. Row 7 lists the value of lifecycle deadweight loss defined in Section 3.4. The ratio of the deadweight loss to the wife's earnings is shown in row 8 and ranges from 3 percent to 5 percent in this example.

\section{Conclusion}

The 1.03 million yen ceiling has been criticized on grounds of efficiency and equity (e.g., Higuchi 1995). Hatta and Oguchi (1999) have proposed removal the threshold for Social Security contributions. A recent policy proposal has called for reducing the earnings threshold to 650 thousand yen, in the hope of making the threshold a non-binding constraint (Ministry of Health, Labour and Welfare 2001). To my knowledge, however, most discussions on this topic are based on a static labor supply framework.

In this paper I derive the optimal labor supply decisions under a dynamic model with endogenous retirement, assuming that the 1.03 million yen ceiling is present. The results show that labor supply choices in a dynamic model have 
important features that are not captured by the static models. When a woman optimizes her labor supply over multiple years, she still tends to choose her annual hours so that her earnings are equal to the threshold. In unconstrained years, however, she tends to increase her hours (the spillover effect). In other words, she partially offsets the work disincentive effects of the means-tested transfer by increasing her work effort in other years. One consequence of the spillover effect is delayed retirement. The dynamic model also has implications for the welfare cost of the ceiling. The dynamic deadweight loss can be expressed as a sum of within-period terms, but the individual terms are not equal to the deadweight loss usually measured in a static labor supply framework.

A recent model by French (2005), which analyzes the dynamic effects of health and Social Security rules in the United States on work effort of older men, has some features similar to the present model. In his policy simulation analysis, French predicts that eliminating the Social Security Earnings Test would delay retirement. The setting of his model is very different from that of the present model so direct comparisons cannot be made. Nevertheless, note that the spillover effect described here argues that the presence of a means test tends to delay retirement.

Since evidence suggests that female part-time workers in Japan have a strong attachment to the labor force, more attention should be paid to the dynamic impact of the 1.03 million yen ceiling on female labor supply and on its distributional consequences. While this analysis is mainly motivated by the retirement behavior of female part-time workers in Japan (micro-level panel data for this population are currently unavailable), similar considerations may influence the choice of young women to re-enter the part-time workforce. Furthermore, this type of dynamic analysis may be useful in understanding the effects of other means-tested trans- 
fers.

\section{Appendix}

This appendix explains the algorithm employed to derive optimal allocations under the MTT regime. The present problem differs from a standard optimization problem in that the static budget constraint has a discontinuous dip; the choice set is therefore non-convex. The problem becomes complicated at the point where the optimal hours schedule makes the transition between a state not receiving benefits and a state receiving benefits. In order to obtain the optimal allocation for the household, I first use the Maximum Principle technique to derive a candidate solution. While this algorithm is computationally simple, for some asset levels it fails to find an allocation that satisfies the budget constraint. This can happen when there are two allocations with similar dynamic utility, for which the timing of the transition differs by one year. For example, when there is one allocation for which the threshold becomes binding in year 3 and another for which the threshold becomes binding in year 4 , if both give a similar level of utility then the Maximum Principle algorithm cannot find the optimum. In such cases a small change in the the marginal utility of assets $(\lambda)$ has a large effect on the final asset level, changing from a large positive value to a large negative value. The source of this jump is the discontinuity created by the transfer payment. In such cases, an approximate solution is found by evaluating the value function numerically using dynamic programming techniques.

The value function is simple to calculate, since $\alpha_{t}$ always increases with time. This means that the wife's working hours will never increase as she ages. Once a household starts to receive transfer benefits, it therefore continues to do so until the 
final period. In the following sections, the Maximum Principle (MP) procedure and the dynamic programming methods used in this paper are explained in turn.

\section{A.1 MP Procedure}

In searching for the optimal allocation, I restrict the search to those allocations for which consumption is smoothed. In other words, the consumption must satisfy the following relationship:

$$
\frac{u_{c}\left(C_{t+1}, \bar{L}-h_{t+1}, t+1\right)}{u_{c}\left(C_{t}, \bar{L}-h_{t}, t\right)}=\frac{\rho}{1+r} .
$$

Restricting the search for this type of allocations significantly simplifies the solution search.

In order to use the MP technique, define the Hamiltonian function as:

$$
\begin{aligned}
H\left(A_{t}, t\right)= & \rho^{t}\left\{\left(\ln \left(C_{t}\right)+\alpha_{t} \ln \left(\bar{L}-h_{t}\right)\right\}\right. \\
& +\lambda_{t}\left\{r A_{t}+\left(w_{t} h_{t}+T R F_{t}-C_{t}\right)\right\} .
\end{aligned}
$$

$H($.$) is then maximized with respect to C_{t}$ and $h_{t}$, subject to equations (3) and (4) in the text. The intertemporal arbitrage condition gives

$$
\lambda_{t}=\frac{\lambda_{0}}{(1+r)^{t}}
$$

which is a standard condition in intertemporal labor supply models. Note that $\lambda_{t}$ in equation (A2) is different from $\lambda$ in the text; $\lambda_{0}$ is equal to $\lambda$ in the text. Substituting equation (A3) into (A2) and rearranging gives

$$
\begin{aligned}
H\left(A_{t}, t\right)= & \rho^{t}\left[\left\{\left(\ln \left(C_{t}\right)+\alpha_{t} \ln \left(\bar{L}-h_{t}\right)\right\}\right.\right. \\
& \left.+\lambda_{0}\left\{r A_{t}+\left(w_{t} h_{t}+T R F_{t}-C_{t}\right)\right\}\right] .
\end{aligned}
$$


Thus, maximizing $H\left(A_{t}, t\right)$ is equivalent to maximizing $\left\{\ln \left(C_{t}\right)+\alpha_{t} \ln \left(\bar{L}-h_{t}\right)\right\}+$ $\lambda_{0}\left\{r A_{t}+\left(w_{t} h_{t}+T R F_{t}-C_{t}\right)\right\}$.

The solution algorithm for the MP procedure is as follows:

Step 1. Set an initial value for $\lambda_{0}$. Denote this value as $\lambda_{0(1)}$.

Step 2. Find the optimal allocation $\left(C_{t}\right.$ and $h_{t}$ for $\left.t=0,1, \cdots, T\right)$ given $\lambda_{0(1)}$, by maximizing (A2) with respect to $C_{t}$ and $h_{t}$ subject to the constraints (3) and (4) in the text. Denote this allocation as $C_{(1)}$ and $h_{(1)}$, where $C_{(1)}$ is the consumption schedule $\left(C_{0(1)}, C_{1(1)}, \cdots, C_{T(1)}\right)$ and $h_{(1)}$ is the labor supply schedule $\left(h_{0(1)}, h_{1(1)}, \cdots, h_{T(1)}\right)$. A subscript in parentheses stands for the iteration number.

Step 3. Check whether $C_{(1)}$ and $h_{(1)}$ satisfy the budget constraint (equation (2) in the text). Then set $\lambda_{0}$ for the next step $\left(\lambda_{0(2)}\right)$ to a value that satisfies the budget constraint given $h_{(1)}$.

Step 4. Repeat steps 1 to 3 until $\lambda_{0}$ converges to a value that is consistent with the budget constraint.

In Step 2, the household decides whether or not it should receive benefits for each period from $t=0$ to $T$. If it decides to receive benefits, then $H($.$) becomes$

$$
H\left(A_{t}, t\right)=\rho^{t}\left[u\left(C_{t}^{B}, h_{t}^{B}, t\right)+\lambda_{0}\left\{r A_{t}+\left(w_{t} h_{t}^{B}+T R F-C_{t}^{B}\right)\right\}\right],
$$

where the superscript B attached to $C_{t}$ and $h_{t}$ indicates that these optimal consumption and hour schedules are calculated for a state with benefits. If the household decides not to receive benefits, then $H($.) is given by

$$
H\left(A_{t}, t\right)=\rho^{t}\left[u\left(C_{t}^{N B}, h_{t}^{N B}, t\right)+\lambda_{0}\left\{r A_{t}+\left(w_{t} h_{t}^{N B}-C_{t}^{N B}\right)\right\}\right]
$$

where the superscript NB stands for a state with no benefits. From equations (A4) 
and (A5), benefits are received in period $t$ if the following condition is met:

$$
\left\{u\left(C_{t}^{B}, h_{t}^{B}, t\right)-u\left(C_{t}^{N B}, h_{t}^{N B}, t\right)\right\}+\lambda_{0}\left\{\left(w_{t} h_{t}^{B}+T R F-C_{t}^{B}\right)-\left(w_{t} h_{t}^{N B}-C_{t}^{N B}\right)\right\} \geq 0 . \text { (A6) }
$$

It can be shown that the conditions for optimum in the MP algorithm are the same as those using a dynamic programming technique, as long as the value function can be approximated as a linear function of assets.

\section{A.2 The Dynamic Programming Procedure: Evaluation of the Value Function}

I apply the above procedure to a variety of initial asset levels. For some asset values, the MP procedure cannot find the allocation that satisfies the budget constraint and the conditions for utility maximization. In such cases the number of years in which a transfer is not received changes by one (for example, from 3 years to 2 years) due to a small change in the value of $\lambda_{0}$. The dynamic programming technique allows me to find an approximate solution in these cases. I numerically evaluate the value function in the neighborhood of $\lambda_{0}$ obtained from the MP procedure. Note that a change in regime from a state without benefits to a state with benefits only occurs once. To derive the optimal allocation when there is a change in years receiving benefits, the value function is evaluated at grid points of asset levels. For some computationally costly cases, cubic spline interpolation is used to calculate the value function at relevant asset levels. For this purpose I use the GAUSS codes of cubic spline routine, which was written by Paul Söderlind. ${ }^{21}$ Using the above procedure, the value function is calculated on a grid covering initial asset levels between 8 million and 20 million yen, with an increment of 100,000

\footnotetext{
${ }^{21}$ This code is distributed at the following web site: http://www.american.edu/academic.depts/cas/econ/gaussres/regress/c_spline/c_spline.htm.
} 
yen, for the parameter values shown in Table 1. The hours schedules for initial asset levels higher than 20 million yen are qualitatively similar to those obtained when $A_{0}$ is equal to 20 million yen.

\section{References}

Abe, Y. (2001) Employees' Pension Benefits and the Labor Supply of Older Japanese Workers, 1980s-1990s. In: Seiritsu Ogura, Toshiaki Tachibanaki and David Wise (eds) Aging Issues in the United States and Japan. The University of Chicago Press, Chicago London, 273-305.

Abe, Y. (2003) Fringe Benefit Provision for Female Part-time Workers in Japan. In: Seiritsu Ogura, Toshiaki Tachibanaki, and David Wise (eds) Labor Markets and Firm Benefit Policies in Japan and the United States. The University of Chicago Press, Chicago London, 339-370.

Abe, Y. (2008) A cohort analysis of male and female employment in Japan. Mimeo, Hokkaido University.

Abe, Y. and F. Ohtake (1997) The Effects of Income Tax and Social Security on the Part-time Labor Supply in Japan. Review of Social Policy No. 6: 45-64.

Akabayashi, H. (2006) The labor supply of married women and spousal tax deductions in Japan -a structural estimation Review of Economics of the Household 4:349-378.

Altonji, J. (1986) Intertemporal Substitution in Labor Supply: Evidence from Micro Data. Journal of Political Economy 94:3 S176-S215.

Auerbach, A. and L. Kotlikoff (1987) Dynamic Fiscal Policy. Cambridge University Press, Cambridge.

Blackorby, B.C., D. Donaldson and S. Molony (1984) Consumer's Surplus and 
Welfare Change in a Simple Dynamic Model. Review of Economic Studies 51: 171-176.

Blundell, R. and T. MaCurdy (1999) Labor Supply: A Review of Alternative Approaches. In: Ashenfelter, O. and D. Card (eds) Handbook of Labor Economics. Volume 3A, Elsevier Science B.V., Amsterdam, 1559-1695.

Blundell, R. and I. Walker (1986) A Life Cycle Consistent Empirical Model of Labour Supply using Cross-Section Data. Review of Economic Studies 53: $539-558$.

Browning, M., A. Deaton, and M. Irish (1985) A Profitable Approach to Labor Supply and Commodity Demands over the Life-Cycle. Econometrica 53(3): $503-543$.

Burtless, G. and R. Moffitt (1985) The Joint Choice of Retirement Age and Postretirement Hours of Work Journal of Labor Economics 3: 209-236.

French, E. (2005) The Effects of Health, Wealth, and Wages on Labour Supply and Retirement Behavior. Review of Economic Studies 72: 395-427.

Friedberg, L. (2000) The Labor Supply Effects of the Social Security Earnings Test. The Review of Economics and Statistics 82: 48-63.

Gustman, A. and T. Steinmeier (1986) A Structural Retirement Model. Econometrica 54(3): 555-584.

Gruber, J. (2000) Health Insurance and the Labor Market. In: Cuyler,A.J. and J. Newhouse (eds) Handbook of Health Economics. Volume 1, Elsevier Science B.V., Amsterdam, 645-706.

Hatta, T. and T. Oguchi (1999) Pension Reform (Nenkin Kaikaku ron) Nihon Keizai Simbun Sha, Tokyo (in Japanese).

Heckman, J., L. Lochner and R. Cossa (2003) Learning by Doing Vs. On-the- 
Job-Training: Using Variation Induced by the EITC to Distinguish between Models of Skill Formation. In: Phelps, E. (ed) Designing inclusion: Tools to raise low-end pay and employment in private enterprise Cambridge University Press, Cambridge, 74-130.

Higuchi, Y. (1995) Economic Consequences for Policies to Protect Low-income wives. (Sengyo shufu hogoseisaku no keizaiteki kiketsu.) In: Hatta, T. and N. Yashiro (eds) Economic Analysis of Policies Protecting the Poor (Jyakusha Hogo Seisaku no Keizai Bunseki) Nihon Keizai Shimbun Sha, Tokyo (in Japanese) 185-219.

Hoynes, H. (1996) Welfare Transfers in Two-Parent Families: Labor Supply and Welfare Participation under AFDC-UP. Econometrica 64(2): 295-332.

Hyslop, D. (2001) Rising U.S. Earnings Inequality and Family Labor Supply: The Covariance Structure of Intrafamily Earnings. American Economic Review 91(4): 755-777.

Keen, M. (1990) Welfare Analysis and Intertemporal Substitution. Journal of Public Economics 42: 47-66.

MaCurdy, T. (1981) An Empirical Model of Labor Supply in a Life-cycle Setting. Journal of Political Economy 89: 1059-1085.

Ministry of Health, Labor and Welfare (2001) Committee Report on Pension Reform in light of the Changes in Women's Lifestyle (Josei no life-style no henka tou ni taiou sita nenkin no arikata ni kansuru Kento kai houkoku-sho) Tokyo (in Japanese).

Nagase, N. (2001) Is the Upper Limit of 1.03 Million Yen Significant in Determining a Wage Rate for Part-timers? (Part no Chingin ni 103 man-en no Kabe ha Juyo ka) The Japanese Journal of Labour Studies 489: 60-61 (in Japanese) 
Nagase, N. and K. Nawata (2005) Changes in taxes and Social Security system on part-time labor supply. (Part no zeisei, shakai-hoken seido no henkou to roudou kyoukyu heno eikyo.) Paper presented at the 2005 Fall Meeting of the Japanese Economic Association (in Japanese).

Ohtake, F. (2000) Income Differentials in the 1990s. (90-nendai no shotoku kakusa.) The Japanese Journal of Labour Studies, 480 2-11 (in Japanese).

Ohtake, F and H. Yamaga (2004) Effects of old-age pension system for active employees on the labor supply of elderly male workers. In: Tachibanaki, T. (ed) The Economics of Social Security in Japan. Edward Elgar Publishing, Cheltham Northampton 136-169.

Oishi, A. (2003) Tax, Social Security and Married Women's Labor Supply. (Yuhaigu Josei no Rodo Kyokyu to Zeisei, Shakaihosho-Seido.) The Quarterly of Social Security Research 39(3) 286-300.

Rust, J. and C. Phelan (1997) How Social Security and Medicare Affect Retirement Behavior in a World of Incomplete Markets. Econometrica 65(4): 781831.

Sakata, K. and C. R. McKenzie (2006) The Impact of the Tax Reform in 2004 on the Female Labour Supply in Japan, Mimeo.

Sefton, J., J. Van de Ven and M. Weale (2005) Means Testing and Retirement Choices in Europe: A Comparison of the British and Danish Systems. Fiscal Studies 26(1) 83-118.

Yamada, K. (2004) The Labor Supply Responses to the 1990's Income Tax Reforms in Japan. Paper presented at the 2004 Spring Meeting of Japanese Economic Association. 
Table 1: Parameter Values for the Numerical Example

Utility Function Parameters

\begin{tabular}{|l|l|r|}
\hline$\alpha_{0}$ & Value attached to leisure & 0.85 \\
\hline $\mathrm{g}_{\alpha}$ & growth rate for $\alpha\left(\alpha_{\mathrm{t}}=\alpha_{0} \exp \left(\mathrm{g}_{\alpha} \mathrm{t}\right)\right)$ & 0.05 \\
\hline$\rho$ & discount rate $(=1 /(1+\mathrm{r}))$ & 0.9804 \\
\hline \hline $\mathrm{L}$ & time endowment (in annual hours) & 4000 \\
\hline $\mathrm{T}+1$ & $\begin{array}{l}\text { Number of years for the optimization } \\
(0,1, \ldots . \mathrm{T})\end{array}$ & 25 \\
\hline
\end{tabular}

Policy Parameters

\begin{tabular}{|l|l|r|}
\hline$\theta$ & (threshold for earnings, in yen) & $1,030,000$ \\
\hline TRF & (Transfer Payment per year, in yen) & 210,000 \\
\hline
\end{tabular}

Wage and Assets

\begin{tabular}{|l|l|l|}
\hline $\mathrm{W}_{\mathrm{t}}$ & (Hourly Wage, in yen) & \multicolumn{1}{|c|}{850} \\
\hline $\mathrm{A}_{0}$ & (Initial Asset, in yen) & ranges from \\
& & $\begin{array}{l}8 \text { million yen to } \\
20 \text { million yen }\end{array}$ \\
\hline $\mathrm{r}$ & & \multicolumn{1}{c}{0.02} \\
\hline
\end{tabular}


Table 2 Labor Supply Schedules and Deadweight Loss

\begin{tabular}{|c|c|c|c|}
\hline Asset Level (in million yen) & \multicolumn{3}{|c|}{9} \\
\hline Threshold Value (in million yen) & \multicolumn{3}{|c|}{1.03} \\
\hline & MTT Regime & Lump Sum Transfer & Transfer Nonexistent \\
\hline $\begin{array}{l}\text { (1) Total Number of Years } \\
\text { worked (years) }\end{array}$ & 20 & 19 & 20 \\
\hline \begin{tabular}{|l|l|} 
(2) Number of years \\
worked with earnings $<$ threshold
\end{tabular} & 17 & 8 & 8 \\
\hline $\begin{array}{l}\text { (3) Total Number of Hours } \\
\text { worked (in hours, } \\
\text { not discounted) }\end{array}$ & 23606 & 25993 & 28678 \\
\hline $\begin{array}{l}\text { (4) Total Number of Hours worked } \\
\text { in the unconstrained years under } \\
\text { the MTT Regime, at the beginning } \\
\text { (in hours, not discounted) }\end{array}$ & $\begin{array}{c}\text { [from } \mathrm{t}=0 \text { to } \mathrm{t}=2 \text { ] } \\
\quad 7216\end{array}$ & $\begin{array}{c}\text { [from } \mathrm{t}=0 \text { to } \mathrm{t}=2 \text { ] } \\
6896\end{array}$ & --- \\
\hline \begin{tabular}{|l} 
(5) Total Number of Hours worked \\
in the unconstrained years under \\
the MTT Regime, just before \\
retirement (in hours, not discounted)
\end{tabular} & $\begin{array}{c}\text { [from } \mathrm{t}=13 \text { to } \mathrm{t}=19] \\
4272\end{array}$ & $\begin{array}{c}\text { [from } \mathrm{t}=13 \text { to } \mathrm{t}=19] \\
2865\end{array}$ & --- \\
\hline \begin{tabular}{|l} 
(6) Present Discounted \\
Value of Transfer \\
(in million yen)
\end{tabular} & 3.564 & --- & --- \\
\hline $\begin{array}{l}\text { (7) Deadweight Loss from } \\
\text { the Transfer Scheme } \\
\text { (in million yen) }\end{array}$ & 0.538 & --- & --- \\
\hline $\begin{array}{l}\text { (8) Deadweight Loss/Wife's } \\
\text { Earnings } \\
\end{array}$ & 0.031 & --- & --- \\
\hline
\end{tabular}

\begin{tabular}{|c|c|c|c|}
\hline Asset Level (in million yen) & \multicolumn{3}{|c|}{17} \\
\hline Threshold Value (in million yen) & & 1.03 & \\
\hline Regime & MTT Regime & Lump Sum Transfer & Transfer Nonexistent \\
\hline $\begin{array}{l}\text { (1) Total Number of Years } \\
\text { worked (years) }\end{array}$ & 18 & 16 & 17 \\
\hline $\begin{array}{l}\text { (2) Number of years } \\
\text { worked with earnings }<\text { threshold }\end{array}$ & 18 & 7 & 7 \\
\hline $\begin{array}{l}\text { (3) Total Number of Hours } \\
\text { worked (in hours, } \\
\text { not discounted) }\end{array}$ & 17133 & 20058 & 22842 \\
\hline $\begin{array}{l}\text { (4) Total Number of Hours worked } \\
\text { in the unconstrained years under } \\
\text { the MTT Regime, at the beginning } \\
\text { (in hours, not discounted) }\end{array}$ & 0 & --- & --- \\
\hline $\begin{array}{l}\text { (5) Total Number of Hours worked } \\
\text { in the unconstrained years under } \\
\text { the MTT Regime, just before } \\
\text { retirement (in hours, not discounted) }\end{array}$ & $\begin{array}{c}\text { [from } t=10 \text { to } t=17] \\
5016\end{array}$ & $\begin{array}{c}\text { [from } \mathrm{t}=10 \text { to } \mathrm{t}=17] \\
3318\end{array}$ & --- \\
\hline $\begin{array}{l}\text { (6) Present Discounted } \\
\text { Value of Transfer } \\
\text { (in million yen) }\end{array}$ & 4.182 & --- & --- \\
\hline $\begin{array}{l}\text { (7) Deadweight Loss from } \\
\text { the Transfer Scheme } \\
\text { (in million yen) }\end{array}$ & 0.669 & --- & --- \\
\hline $\begin{array}{l}\text { (8) Deadweight Loss/Wife's } \\
\text { Earnings }\end{array}$ & 0.052 & --- & --- \\
\hline
\end{tabular}


Figure 1a: The Static Budget Constraint

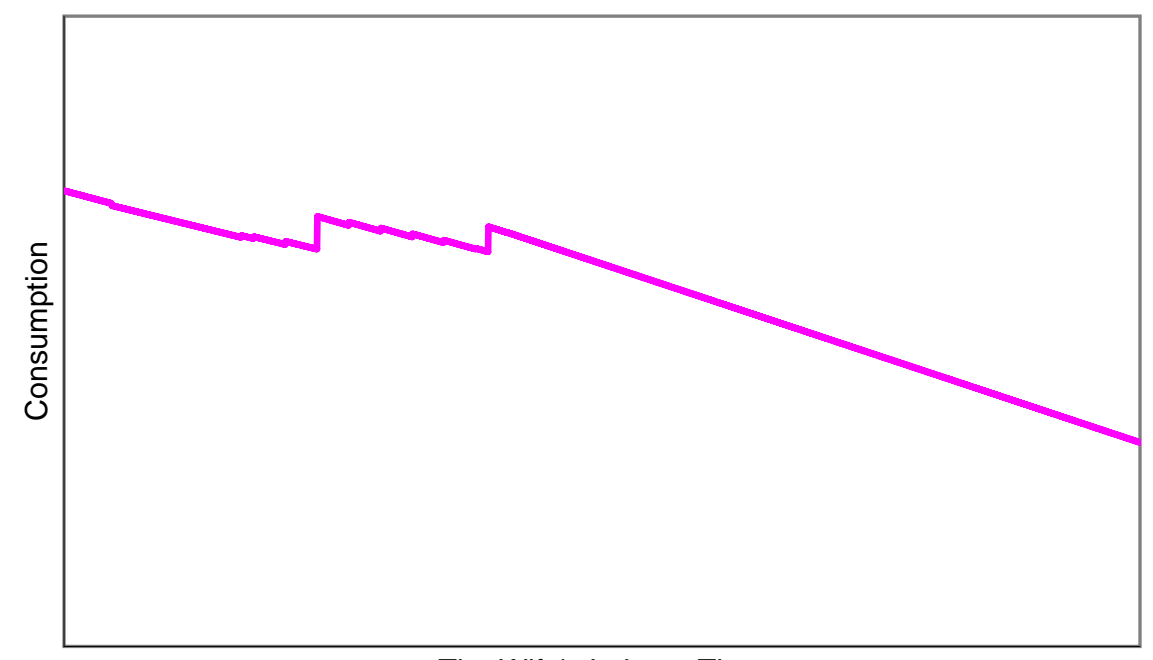

The Wife's Leisure Time

Figure 1b: Transfer System Assumed in the Model

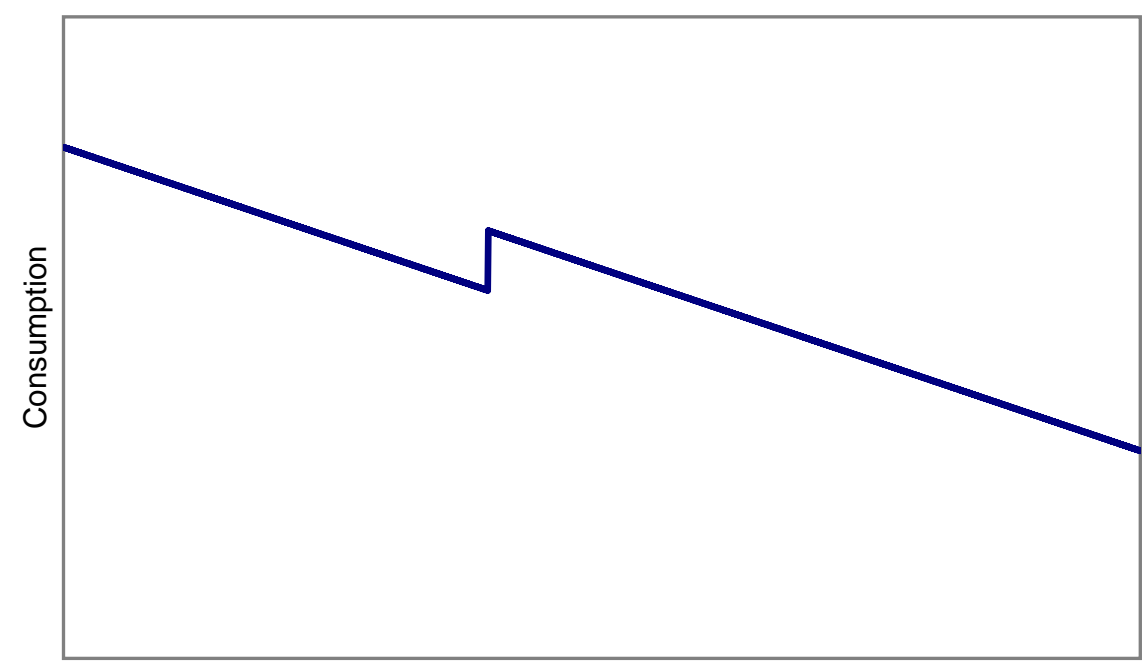

The Wife's Leisure Time 
Figure 2: Earnings distribution of married women working part-time, by age group

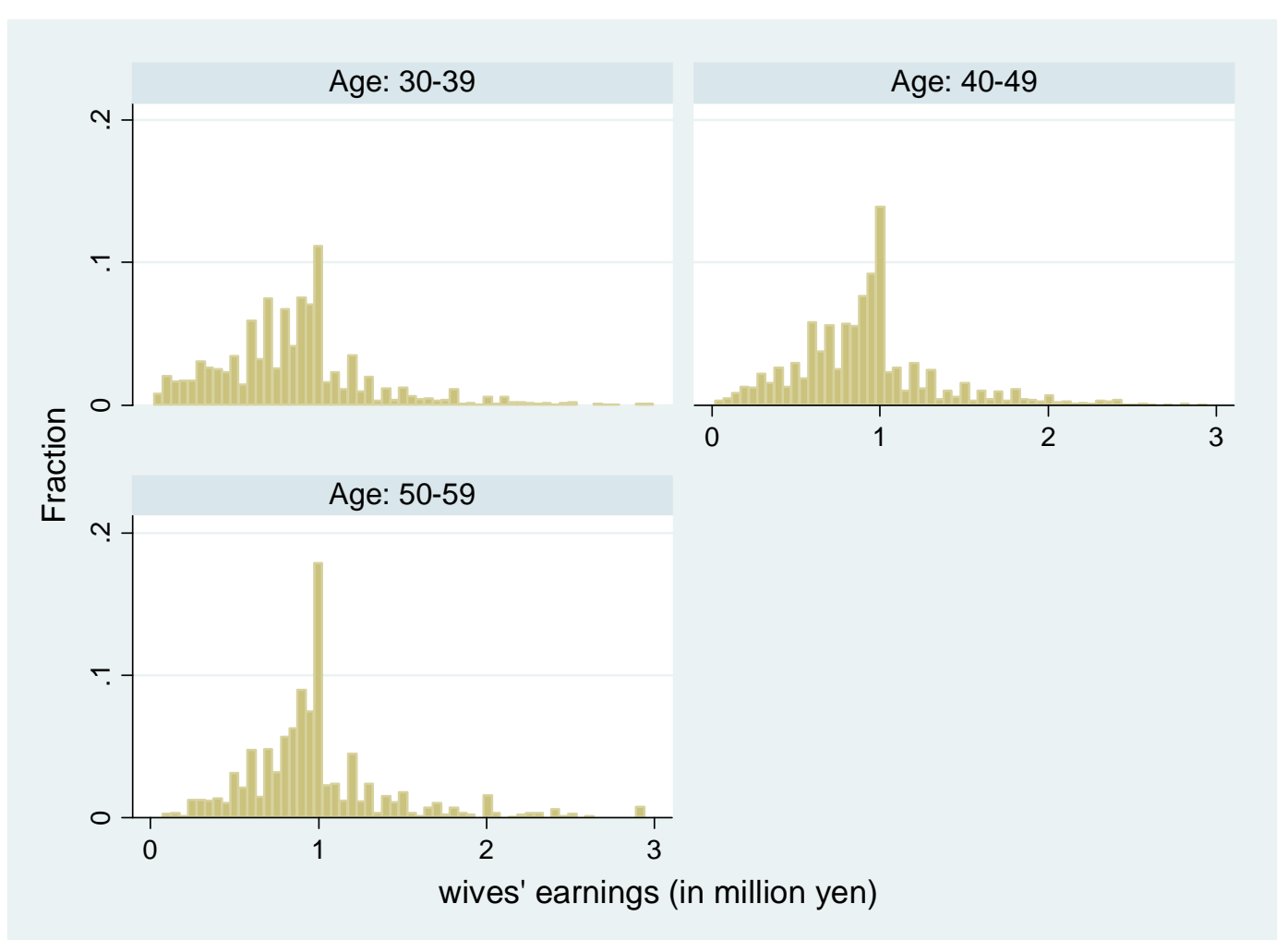

Source: Resampled data of NSFIE (2004) .

Note: The figures are drawn from the sample of married women working part-time.

Individuals with earnings over 3 million yen are excluded.

The proportion of earnings over 3 million yen is less than 1.4 percent for each of the three

age groups.

Observations are weighted by the sampling weight.

The number of observations is 1363 for age 30-39, 2136 for age 40-49, and 520 for age 50-59. 
Figure 3: Cohort profiles of part-time employment ratio of married women
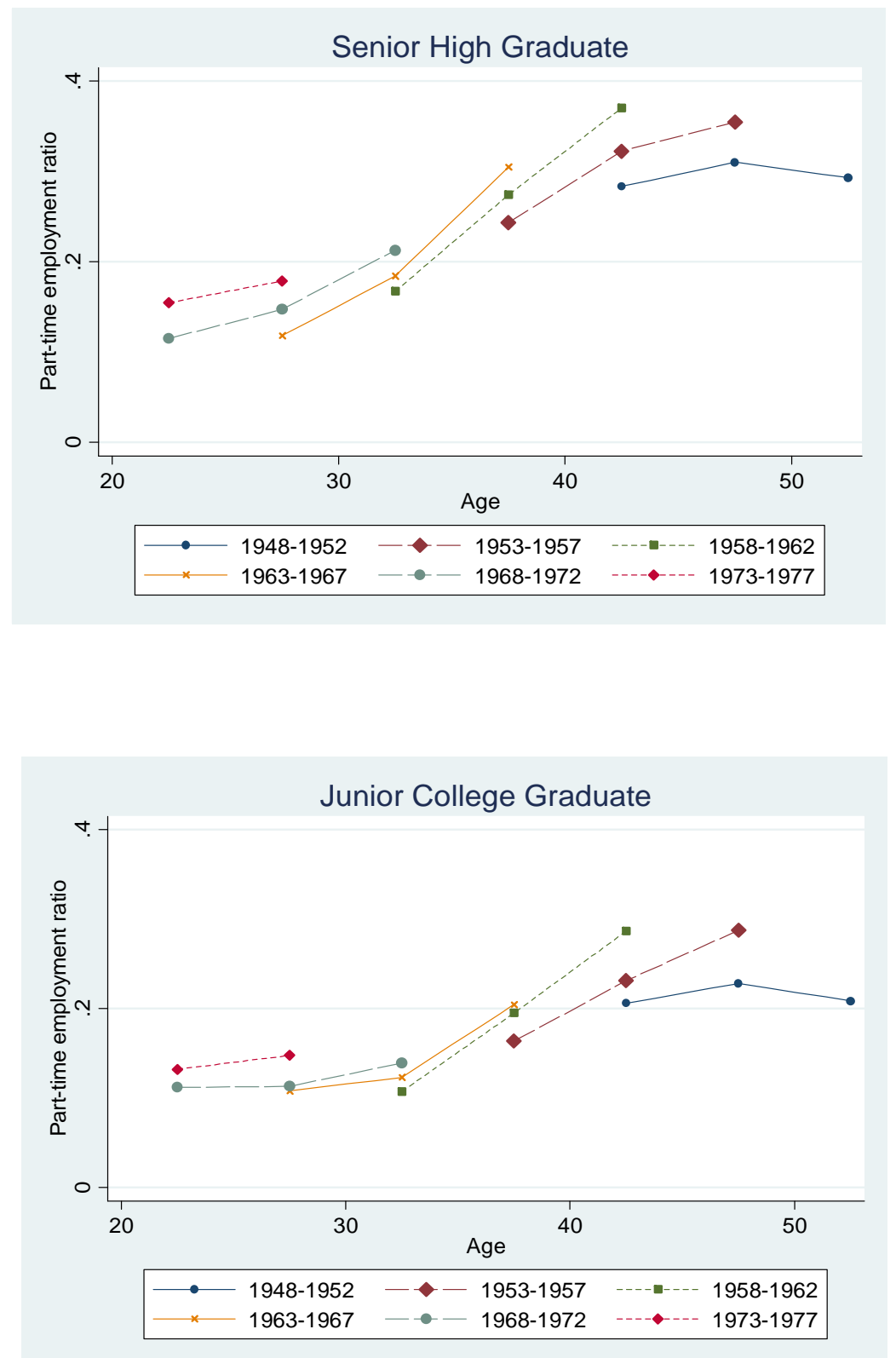

Source: Resampled data of ESS (1992-2002).

Note: The part-time employment ratio is the number of part-time employees to population. The legends indicate the birth years of each cohort.

Observations are weighted by the sampling weight. 
Figure 4-1: Hours Schedule (Initial Asset=9 million yen)

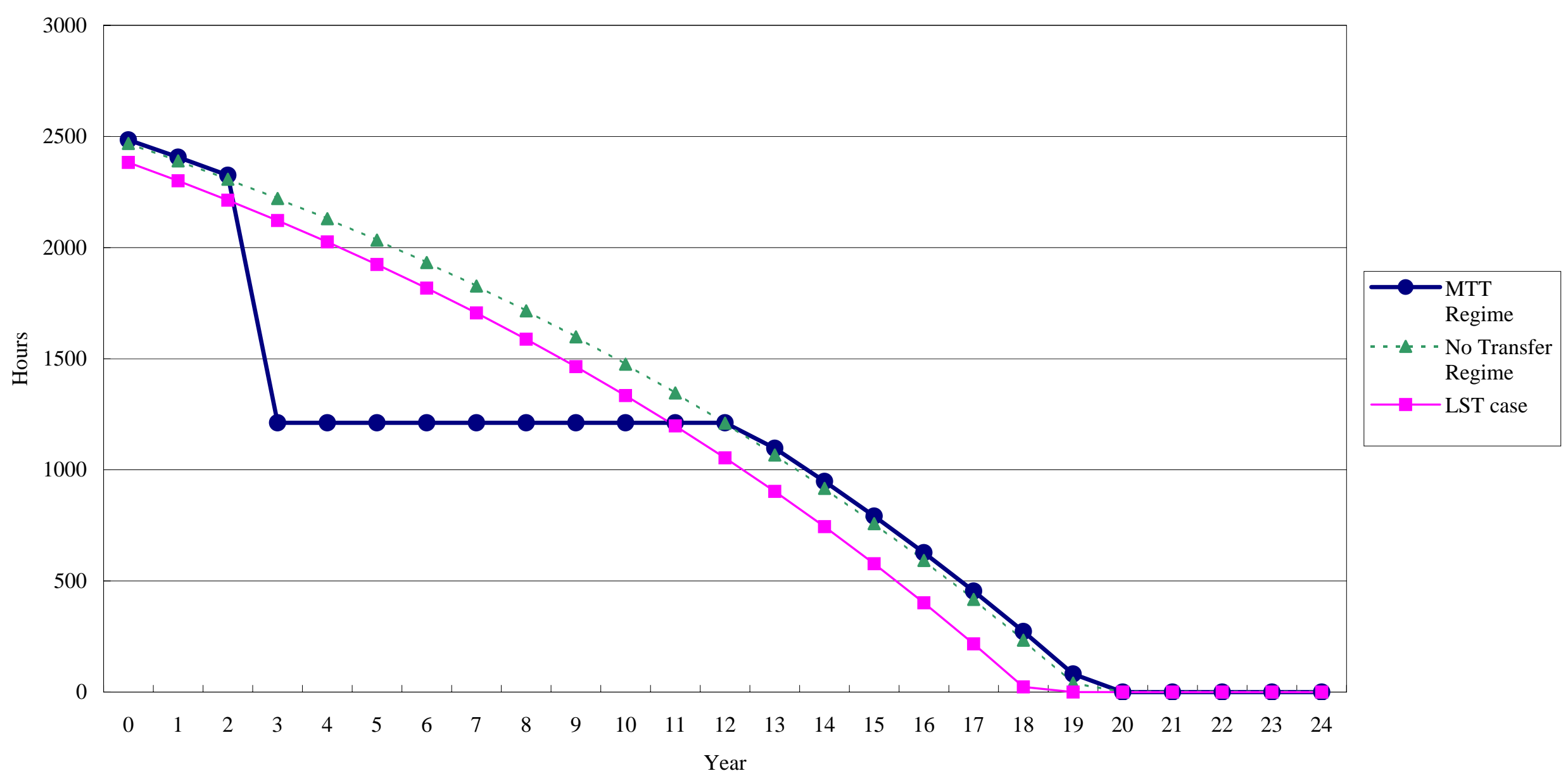


Figure 4-2: Hours Schedule (initial Asset=17 million yen)

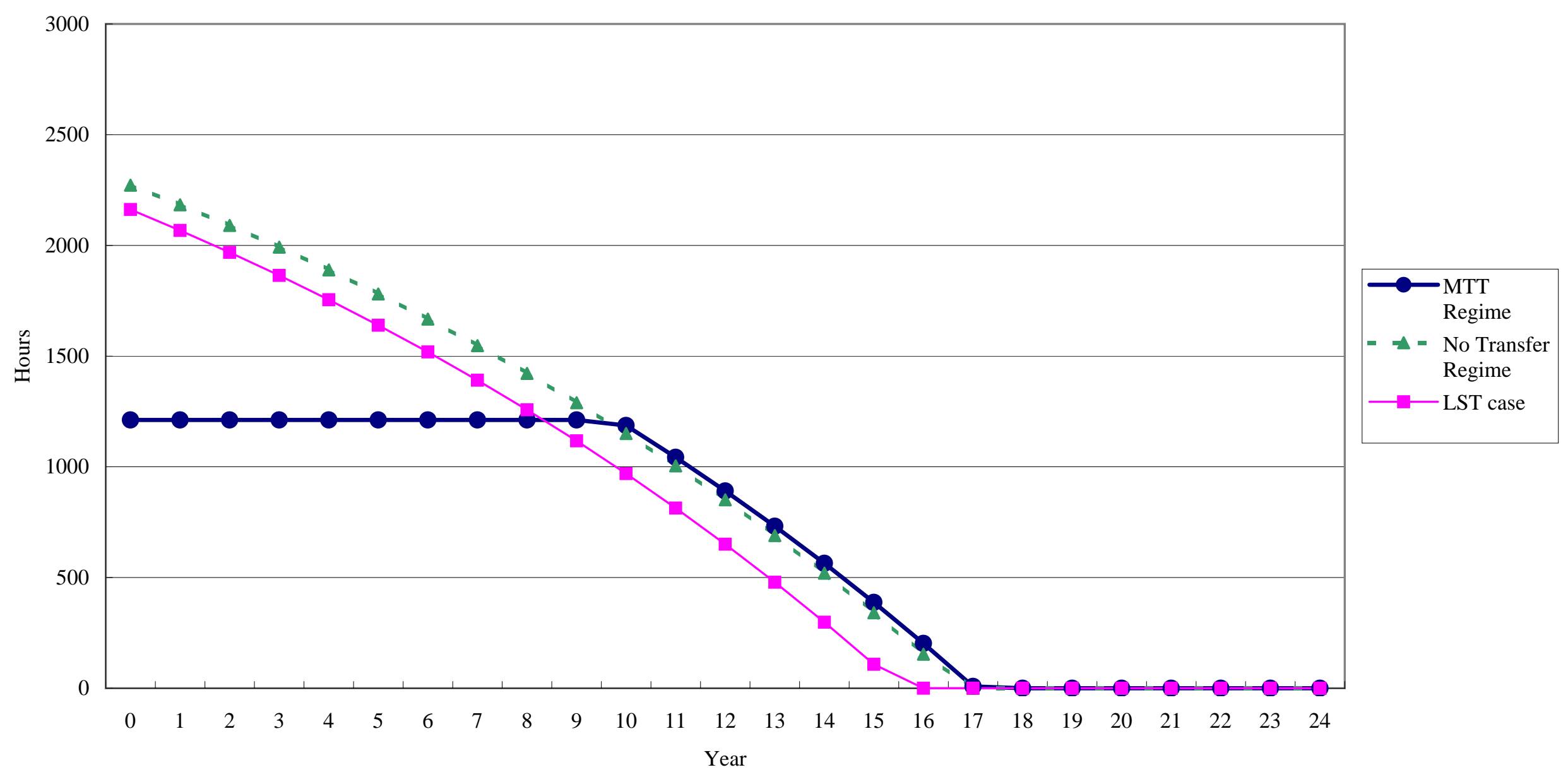

